\title{
Computerized Lung Acoustic Monitoring Can Help to Differentiate between Various Chest Radiographic Densities in Critically III Patients
}

\author{
Shaul Lev ${ }^{a}$ Yael A. Glickman ${ }^{c}$ Ilya Kagan ${ }^{a}$ Maury Shapiro $^{a}$ \\ Osnat Moreh-Rahav ${ }^{b}$ David Dahan $^{\mathrm{a}}$ Jonathan Cohen ${ }^{\mathrm{a}}$ Milana Grinev $^{\mathrm{a}}$ \\ Pierre Singer ${ }^{\mathrm{a}}$ \\ Departments of ${ }^{\mathrm{a}}$ General Intensive Care and ${ }^{\mathrm{b}}$ Radiology, Rabin Medical Center, Petah Tikva, and \\ 'Deep Breeze, Ltd., Or-Akiva, Israel
}

\section{Key Words}

Chest radiography $\cdot$ Consolidation $\cdot$ Lung acoustic monitoring $\cdot$ Lung sound energy $\cdot$ Mechanical ventilation • Pneumonia $\cdot$ Vibration response imaging

\begin{abstract}
Background: Complementary bedside lung monitoring modalities are often sought in order to assist in the differentiation between several lung opacities in the intensive care unit (ICU). Objectives: To evaluate the use of computerized lung acoustic monitoring as a complementary approach in the differentiation between various chest radiographic densities in critically ill patients. Methods: Lung vibration intensity was assessed in 82 intensive care patients using vibration response imaging. Patients were classified according to their primary findings on chest radiography (CXR): consolidation $(n=35)$, congestion $(n=10)$, pleural effusion $(n=15)$, atelectasis/hypoinflation $(n=10)$ and normal findings $(n=$ 12). Sixty patients were mechanically ventilated and 22 patients were spontaneously breathing. Results: Significantly elevated vibration intensity was detected in patients with consolidation, as opposed to pleural effusion, atelectasis and normal CXR ( $p<0.01$, Mann-Whitney $U$ test). Vibration intensity was also increased for congestion, but this increase was not significant. The positive predictive value of CXR lung
\end{abstract}

opacity in combination with increased vibration intensity to detect consolidations and/or congestions was 95\% (20/21). Furthermore, vibration intensity was significantly higher in mechanically ventilated patients compared to spontaneously breathing patients $(p=0.001$, Mann-Whitney U test). Differences related to gender, age and body position were not significant. Conclusions: Computerized lung acoustic monitoring at the bedside was found to be a useful, readily available, noninvasive, adjunctive tool in the differentiation between various CXR densities in critically ill patients.

Copyright $\odot 2010$ S. Karger AG, Basel

\section{Introduction}

While a portable chest radiograph (CXR) remains the most commonly requested radiographic examination in the intensive care unit (ICU) [1], adjunctive bedside pulmonary monitoring methods are often sought to help differentiate between several lung opacities in critically ill patients [2]. Recently, electrical impedance tomography has gained acceptance as a valuable monitoring tool for the care of critical patients $[3,4]$. While useful in the detection of alveolar collapse and recruitment [5] and the monitoring of the development of pneumothoraces $[6$, 7], the diagnostic capability of electrical impedance to-

\section{KARGER}

Fax +4161306 1234 E-Mail karger@karger.ch www.karger.com (c) 2010 S. Karger AG, Basel

0025-7931/10/0806-0509\$26.00/0

Accessible online at:

www.karger.com/res
Shaul Lev, MD

Department of General Intensive Care, Rabin Medical Center

Beilinson Campus, Jabotinski Street 39

Petah Tikva 49100 (Israel)

Tel. +972 3937 6521, Fax +972 3923 2333, E-Mail lev.nirit@gmail.com 
mography is still not fully understood. Ultrasound, on the other hand, has been increasingly used as an adjunctive diagnostic tool in critically ill patients [8], taking a role in the management of airway [9] and thoracic diseases [10]. Recently, Lichtenstein et al. [11] used ultrasound to differentiate between pneumonia and resorptive atelectasis. The authors reported that a dynamic air bronchogram could be used as a sign of alveolar consolidation, ruling out atelectasis. Despite these promising developments, the need of high proficiency is one of the greatest challenges for wide adoption of ultrasound in the ICU [12] and therefore, there is still a need for interpretation-free modalities that could assist in the management of lung diseases. Lung sound monitoring [1321] has been suggested as a potential tool to aid in the diagnosis of lung congestion [22] and as a method to assist in the differentiation between pneumonia and healthy controls [23-26]. While becoming readily available in clinical settings [27-30], computerized lung sound monitoring systems have only recently been introduced in critical care [31].

Vibration response imaging (VRI) is a monitoring system that produces a functional, dynamic image of lung sounds during the respiratory cycle [32, 33]. Its diagnostic capability has been described in non-critically ill patients, particularly in pneumonia [34], pleural effusion [35] and pneumothorax [36]. Experience in critical care includes assessment of asymmetric lung diseases [37] as well as the setting of mechanical ventilator parameters such as mode of ventilation [38] or positive end-expiratory pressure [39]. The aim of the present study was to evaluate the use of computerized lung acoustic monitoring as a complementary approach in the differentiation between various chest radiographic densities in critically ill patients.

\section{Patients and Methods}

\section{Patients}

The study was performed in the general ICU of the Rabin Medical Center in Petah-Tikva, Israel. The study protocol was approved by the institutional review board and informed consent was obtained from all patients or their next-of-kin. Vibration response measurements were investigated in a prospective trial.

\section{Inclusion and Exclusion Criteria}

Patients enrolled in the study were adults (18-85 years old) with a body mass index $>20$ to ensure good adherence of the array of sensors. Exclusion criteria included a body habitus or skin condition that would interfere with sensor placement; the presence of a cardiac pacemaker and pregnancy.

\section{Study Design}

Routine CXRs were scored by a board-certified radiologist blinded to the patients' clinical information. The radiologist was specifically asked to classify findings as primary, secondary and tertiary. Lung sound measurements recorded at the time of CXR were considered for analysis. Recording quality was assessed according to pre-determined criteria; recordings with an average vibration intensity level below a pre-defined threshold $(<1$ in the energy bar of the imaging display) were excluded [38]. Two patients were excluded from this study based on these criteria. Mode of mechanical ventilation, tidal volume, respiratory rate, fraction of inspired oxygen and pulse oximeter oxygen saturation were documented when applicable. To ensure that timing between spontaneous and controlled cycles did not affect the results, spontaneous breathing was maintained whenever available, including in synchronized intermittent mandatory ventilation mode.

\section{Recording Procedure}

The study setup is displayed in figure 1 . The recordings were performed using a VRIxv ${ }^{\mathrm{TM}}$ device (Deep Breeze Ltd., Or-Akiva, Israel) with two arrays of 6 rows $\times 3$ columns piezoelectric sensors or microphones similar to those used in digital stethoscopes. Earlier recordings were performed in sitting position $(n=43)$, using a low suction adherence mechanism. When the supine capability became available, the remainder of the patients $(n=39)$ were recorded in supine position with a bed angle between 30 and $45^{\circ}$. The sensors used in both arrays were identical. The arrays were positioned posterior to the patient's back. When recording with the supine array of sensors, a disposable positioning unit was used to help position the arrays and to reduce risk of cross-contamination. Morphological landmarks such as spine and scapula were used in order to ensure accurate and repeatable placement of the sensor arrays. Excessive secretions were removed by endotracheal and oral suctioning before recording. When applicable, airway pressure and flow waveforms were sampled from the ventilator using a proximal flow sensor inserted in the patient's circuit.

\section{Measurement Output}

Acoustic signals were recorded during 20 s of acquisition time, followed by $40 \mathrm{~s}$ of processing time, and were stored digitally on the system for later review and analysis. A band-pass filter between 150 and $250 \mathrm{~Hz}$ was applied to the data to remove heart and muscle sounds; median filtering was performed to suppress impulse noise, and truncation of samples above an automatically determined signal-to-noise threshold was carried out. A 64-multichannel analog-to-digital converter was used for data acquisition. The system included a 16-bit acquisition level and a sampling rate of $19.2 \mathrm{kHz}$. The resulting signal for each sensor was down-sampled to produce an envelope signal (vibration energy). The output was a gray-scale, two-dimensional dynamic image of the lungs created from a series of 118 still images or frames with each frame representing $0.17 \mathrm{~s}$ of vibration energy; 20 -second recording included up to 10 respiratory cycles. High vibration was represented by dark colors (black) and low vibration by light color (light gray). Since the highest and lowest values were always determined as black or white, each recording was normalized to these values. Data from each sensor were collected separately, and the sums of vibration intensity expressed in arbitrary units (AU) 


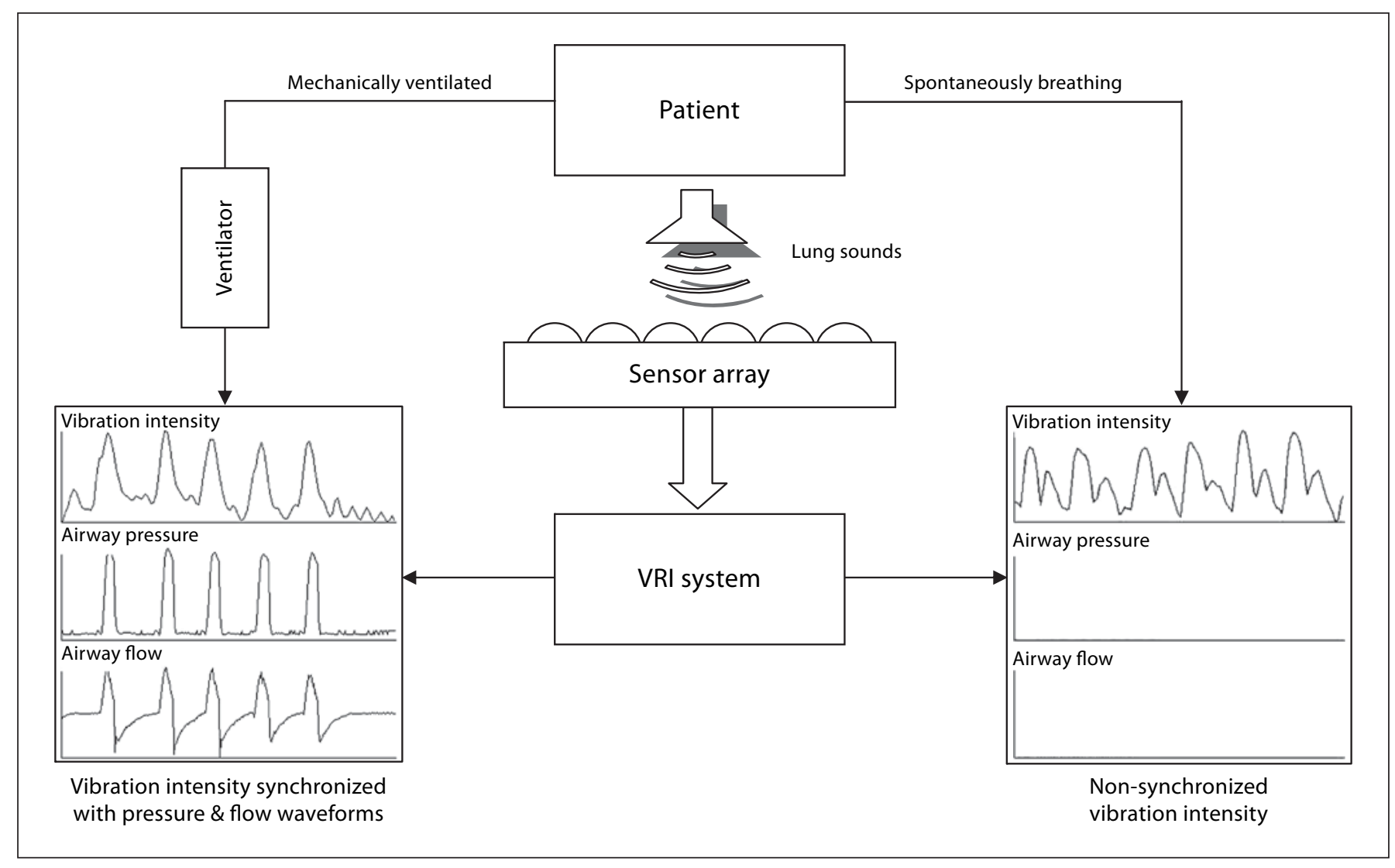

Fig. 1. Schematic diagram describing the elements of the system: patient with acoustic sensor array connected to the VRI system. For a mechanically ventilated patient, lung vibration intensity waveform obtained during a 20 -second recording is synchronized with airway pressure and flow collected from the ventilator. For a spontaneously breathing patient, lung vibration intensity waveform is not synchronized.

in the right and left lungs, as well as the total vibration intensity in both lungs, were computed off-line. The analysis was performed on the data point corresponding to peak inspiratory flow, a specific time point of the respiratory cycle, as indicated in figure 2. In synchronized recordings, the representative data point was automatically selected by the system as the peak inspiratory point of lowest vibration intensity from the 20 -second recording. This data point was referred to as synchronized maximum energy frame. If synchronization was not available, manual selection was performed based on similar criteria used by the automatic selection tool.

\section{Statistical Analysis}

Data are presented using descriptive statistics as means \pm SD. Wilcoxon's signed-ranks test for paired data was used to analyze the data between lungs; the Mann-Whitney $U$ test for unpaired data was employed to analyze the data between different clinical conditions. A p value $<0.05$ was considered significant. Data analyses were performed with statistics software (SPSS, version 11.5.1; SPSS, Chicago, Ill., USA; IFA Services Statistics, Amsterdam; GraphPad Software, San Diego, Calif., USA).

\section{Results}

A total of 82 ICU patients (57 males and 25 females; age $59 \pm 19$ years) were enrolled in the study between April 2007 and February 2008. Twenty-two patients were breathing spontaneously while 60 patients were mechanically ventilated using one of three ventilator types $(\mathrm{Pu}-$ ritan Bennett 840; Tyco Healthcare, Mansfield, Mass., USA; Evita XL or Evita 4, Draeger, Lübeck, Germany; Engström Carestation, General Electric, Madison, Wisc., USA). The majority of the mechanically ventilated patients ( $\mathrm{n}=42 ; 70 \%$ ) were on pressure support mode of ventilation with a level between 8 and $24 \mathrm{~cm} \mathrm{H}_{2} \mathrm{O}$ (mean $17 \pm 5 \mathrm{~cm} \mathrm{H} \mathrm{H}_{2} \mathrm{O}$ ). Sixteen patients (27\%) were ventilated using synchronized intermittent mandatory ventilation and 2 patients (3\%) were ventilated on pressure controlled mode. For mechanically ventilated patients, average tidal volume was $555 \pm 152 \mathrm{ml}$, respiratory rate $21 \pm 7$ breaths/ 
Fig. 2. Example of acoustic data as displayed by the system: vibration response frame at peak inspiration (synchronized maximum energy frame; a) and synchronized vibration intensity graph with ventilator airway pressure and flow waveforms (b).
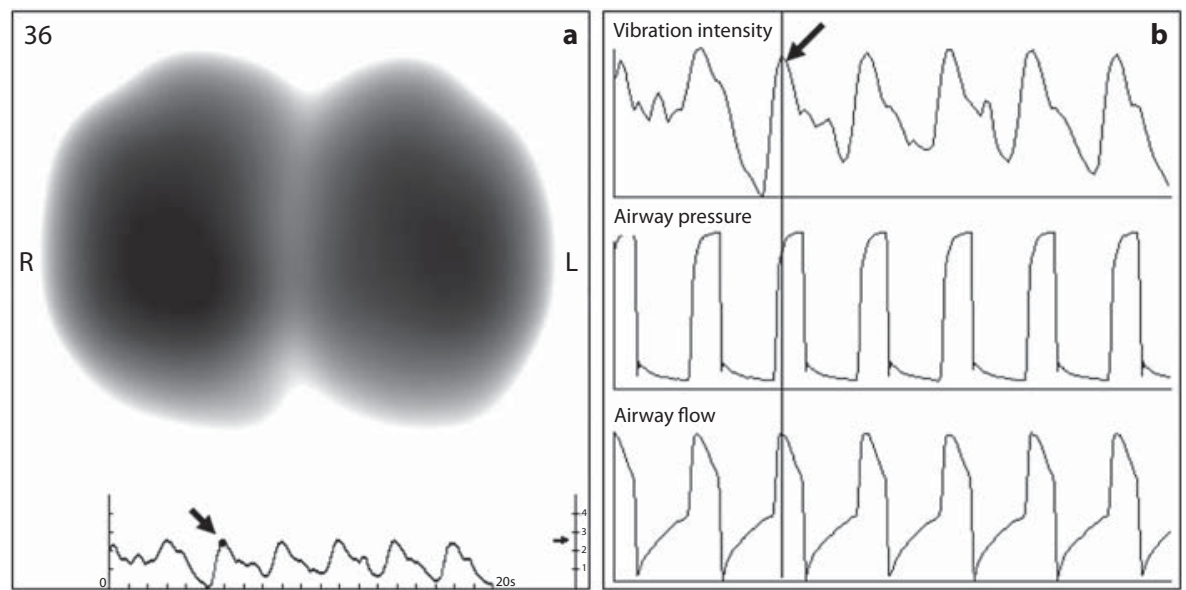

Table 1. Reason for ICU admission of the 82 patients

\begin{tabular}{lrr}
\hline Reason for intubation & $\mathrm{n}$ & $\%$ \\
\hline Pneumonia & 17 & 21 \\
Acute respiratory failure & 10 & 12 \\
Sepsis & 9 & 11 \\
Motor vehicle accident & 8 & 10 \\
Intoxication & 3 & 4 \\
Pancreatitis & 3 & 4 \\
HELLP syndrome and eclampsia & 3 & 4 \\
Cerebrovascular accident & 3 & 4 \\
Interstitial lung disease & 2 & 2 \\
Acute respiratory distress syndrome & 2 & 2 \\
Guillain-Barré syndrome & 2 & 2 \\
Pulmonary embolism & 2 & 2 \\
Acute renal failure & 2 & 2 \\
Others & 16 & 20 \\
\hline
\end{tabular}

Others include chronic obstructive pulmonary disease, facial burns, Legionnaire's disease, myocardial infarct, aspiration, spinal cord transaction, fecal peritonitis, myasthenia gravis, colon resection, mesenterial ischemia, wound infection, acute supratitis, meningitis, diabetic ketoacidosis, cardiopulmonary resuscitation and stroke.

Table 2. Primary CXR findings

\begin{tabular}{lcccl}
\hline Primary finding & $\mathrm{n}$ & $\%$ & $\begin{array}{c}\text { Uni- } \\
\text { lateral }\end{array}$ & $\begin{array}{l}\text { Bi- } \\
\text { lateral }\end{array}$ \\
\hline Consolidation & 35 & 43 & 32 & 3 \\
Congestion & 10 & 12 & 5 & 5 \\
Pleural effusion & 15 & 18 & 11 & 4 \\
Atelectasis/hypoinflation & 10 & 12 & 7 & 3 \\
Normal CXR & 12 & 15 & & \\
\hline
\end{tabular}

min, oxygen saturation $96 \pm 4 \%$ and fraction of inspired oxygen $58 \pm 25 \%$. Patients were not deeply sedated and none was paralyzed. Reasons for ICU admission are described in table 1 . No adverse event related to the measurement was registered.

As summarized in table 2, patients were divided into five groups according to their primary CXR finding: consolidation $(\mathrm{n}=35)$, congestion $(\mathrm{n}=10)$, pleural effusion $(\mathrm{n}=15)$, atelectasis/hypoinflation $(\mathrm{n}=10)$ and normal CXR $(\mathrm{n}=12)$. Among the 70 patients with abnormal appearing findings, 55 had unilateral pathology (79\%) and 15 had bilateral pathology (21\%). Lung vibration intensities recorded from all the sensors at peak inspiration were calculated for each patient and are presented in figure 3. As revealed in figure 3, mean vibration intensity for patients with consolidation was significantly higher than for patients with pleural effusion, normal-appearing CXR and atelectasis ( $<<0.01$, Mann-Whitney U test). This difference was maintained when considering only the patients mechanically ventilated on pressure supportrelated modes $(\mathrm{n}=58, \mathrm{p}=0.03$, Mann-Whitney $\mathrm{U}$ test). A threshold, computed as the mean vibration intensity for normal-appearing CXR plus 5 times the standard deviation (threshold $=18 \times 10^{6} \mathrm{AU}$ ) was used to calculate the positive predictive value. The positive predictive value, defined as the proportion of patients with vibration intensity higher than this threshold that were actually diagnosed with consolidation and/or congestion, was 95\% (20/21). Examples of the CXR and VRI image obtained for a patient with consolidation are presented in figure 4 . As shown in figure 4, a localized area of high vibration intensity overlaps with the consolidation detected by CXR. Vibration intensity in 4 patients with pneumonia but without consolidation was lower than in 13 patients 
Fig. 3. Individual vibration intensity in 82 ICU patients classified according to primary CXR findings: congestion $(\mathrm{n}=10)$, consolidation ( $\mathrm{n}=35)$, pleural effusion $(\mathrm{n}=15)$, atelectasis/hypoinflation $(\mathrm{n}=$ $10)$ and normal-appearing CXR $(n=12)$. Means \pm SD are indicated as well as significant $\mathrm{p}$ values (Mann-Whitney $\mathrm{U}$ test). The suggested threshold for detection of consolidations at $18 \times 10^{6} \mathrm{AU}$ is also specified.

Fig. 4. CXR and VRI at peak inspiration (synchronized maximum energy frame) of a patient with right consolidation. Increased vibration intensity area, represented with darker (black) colors in VRI, overlaps with the consolidation detected by CXR. Because of normalization, this high intensity overshadows the appearance of the left lung.
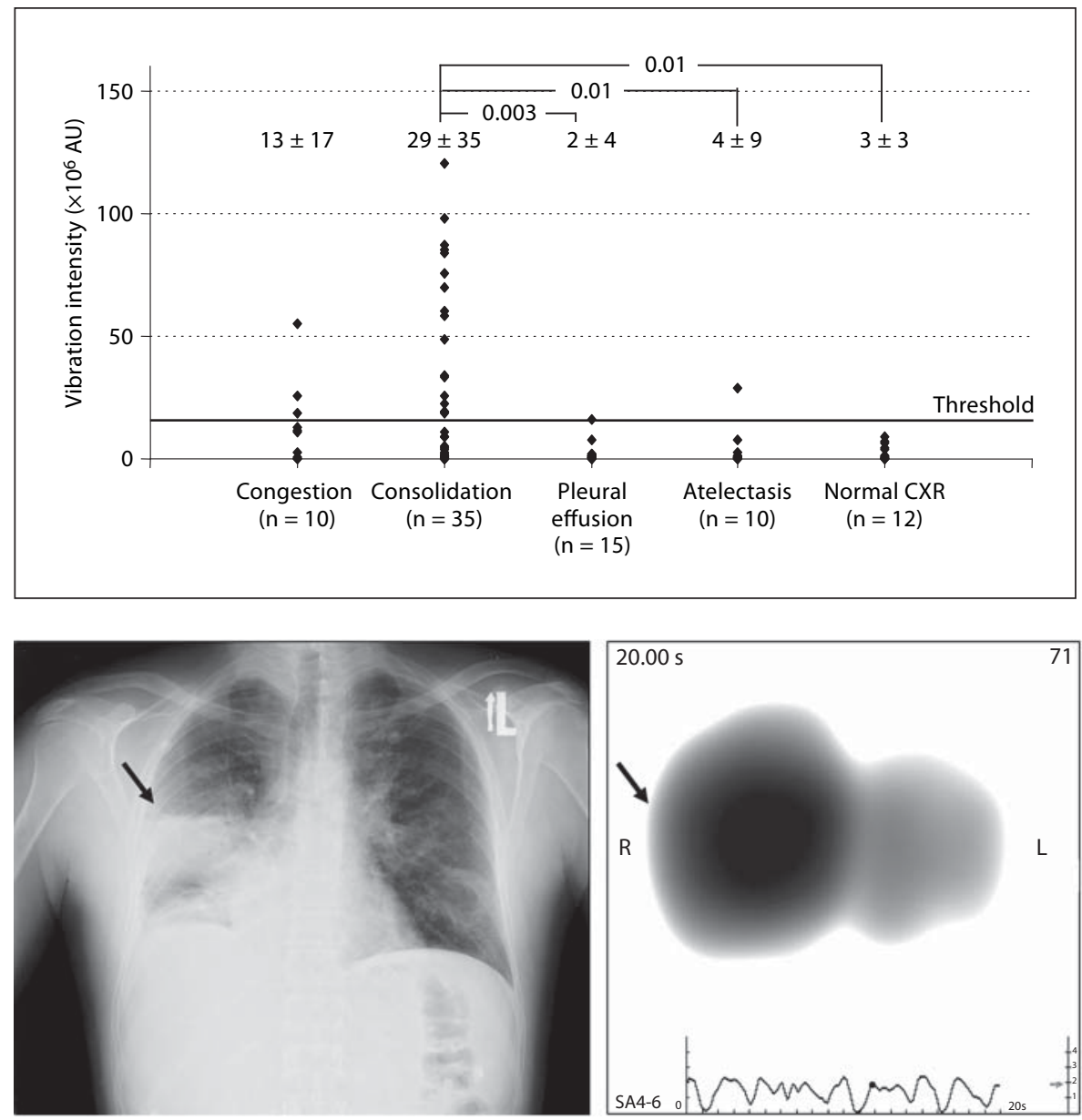

with pneumonia and consolidation ( $8 \pm 14$ vs. $22 \pm 29$ $\left.\times 10^{6} \mathrm{AU}\right)$. Finally, in patients with unilateral disease, less vibration intensity was recorded from the sick lung compared to the other lung, especially in 18 patients with pleural effusion or atelectasis $\left(1 \pm 2\right.$ vs. $2 \pm 5 \times 10^{6} \mathrm{AU}$, $\mathrm{p}=0.05$, Wilcoxon matched-pairs signed-ranks test).

The effect of gender, age and body position on vibration intensity was studied in homogeneous subgroups of patients. As shown in table 3, vibration intensity from spontaneously breathing patients $(n=20)$ was more than three times lower than for mechanically ventilated patients $(n=17)$. This difference was significant $(p=0.001$, Mann-Whitney U test). Furthermore, the ratio between vibration intensity in apical and diaphragmatic areas was significantly higher in mechanically ventilated patients than in spontaneously breathing patients $(p=0.006$, Mann-Whitney U test). As shown in table 3, differences related to gender, age, body position, oxygen saturation, tidal volume or respiratory rate were not significant.

\section{Discussion}

In this study, we used a VRI system in order to differentiate between various CXR densities in critically ill patients. Furthermore, we used homogeneous groups of patients to evaluate the effect of patient demographics, body position and ventilatory status on vibration intensity. Our results document the increase in vibration intensity in patients with consolidation and/or congestion as opposed to other lung pathologies such as atelectasis or pleural effusion. Furthermore, significantly higher energy was obtained in mechanically ventilated patients as opposed to spontaneously breathing patients.

The increased vibration intensity related to consolidation in our study on critically ill patients is compatible with results of Murphy et al. [26] comparing 50 non-critically ill patients diagnosed with pneumonia and 50 control subjects. In particular, the authors demonstrated that adventitious lung sounds were more common in pneu- 
Table 3. Comparing lung vibration intensity and ratio between vibration intensity in the apical and diaphragmatic areas in different subgroups of patients classified according to ventilatory status, gender, age, body position, oxygen saturation, tidal volume and respiratory rate

\begin{tabular}{|c|c|c|c|c|c|c|c|}
\hline Factor & Patient group used & Status & $\mathrm{n}$ & $\begin{array}{l}\text { Vibration } \\
\text { intensity } \\
\times 10^{6} \mathrm{AU}\end{array}$ & $\mathrm{p}$ value & $\begin{array}{l}\text { Ratio between vibra- } \\
\text { tion intensity in api- } \\
\text { cal and diaphrag- } \\
\text { matic areas }\end{array}$ & $\mathrm{p}$ value \\
\hline $\begin{array}{l}\text { Ventilatory } \\
\text { status }\end{array}$ & $\begin{array}{l}\text { patients with pleural effusion, } \\
\text { atelectasis or normal CXR }\end{array}$ & $\begin{array}{l}\text { ventilated } \\
\text { non-ventilated }\end{array}$ & $\begin{array}{l}20 \\
17\end{array}$ & $\begin{array}{l}5 \pm 7 \\
1 \pm 2 \\
\end{array}$ & 0.001 & $\begin{array}{l}2.3 \pm 1.9 \\
1.7 \pm 1.4\end{array}$ & 0.006 \\
\hline & $\begin{array}{l}\text { patients with consolidation } \\
\text { or congestion }\end{array}$ & $\begin{array}{l}\text { ventilated } \\
\text { non-ventilated }\end{array}$ & $\begin{array}{r}40 \\
5\end{array}$ & $\begin{array}{r}28 \pm 33 \\
9 \pm 14\end{array}$ & NA & $\begin{array}{l}3.0 \pm 4.8 \\
2.6 \pm 1.5\end{array}$ & NA \\
\hline Gender & all patients & $\begin{array}{l}\text { male } \\
\text { female }\end{array}$ & $\begin{array}{l}57 \\
25\end{array}$ & $\begin{array}{l}15 \pm 25 \\
17 \pm 30\end{array}$ & 0.8 & $\begin{array}{l}1.9 \pm 1.4 \\
2.3 \pm 2.0\end{array}$ & 0.7 \\
\hline Age & $\begin{array}{l}\text { mechanically ventilated patients } \\
\text { with consolidation }\end{array}$ & $\begin{array}{l}<60 \text { years old } \\
\geq 60 \text { years old }\end{array}$ & $\begin{array}{l}17 \\
15\end{array}$ & $\begin{array}{l}38 \pm 40 \\
22 \pm 30\end{array}$ & 0.2 & $\begin{array}{l}2.6 \pm 1.8 \\
2.2 \pm 1.9\end{array}$ & 0.4 \\
\hline $\begin{array}{l}\text { Body } \\
\text { position }\end{array}$ & $\begin{array}{l}\text { mechanically ventilated patients } \\
\text { with consolidation }\end{array}$ & $\begin{array}{l}\text { supine } \\
\text { sitting }\end{array}$ & $\begin{array}{l}20 \\
12\end{array}$ & $\begin{array}{l}35 \pm 34 \\
24 \pm 39\end{array}$ & 0.2 & $\begin{array}{l}2.2 \pm 2.0 \\
2.7 \pm 1.6\end{array}$ & 0.08 \\
\hline $\begin{array}{l}\text { Oxygen } \\
\text { saturation }\end{array}$ & $\begin{array}{l}\text { mechanically ventilated patients } \\
\text { with consolidation }\end{array}$ & $\begin{array}{l}<98 \% \\
\geq 98 \%\end{array}$ & $\begin{array}{l}16 \\
15\end{array}$ & $\begin{array}{l}32 \pm 35 \\
23 \pm 30\end{array}$ & 0.5 & $\begin{array}{l}2.1 \pm 1.3 \\
2.6 \pm 2.2\end{array}$ & 1.0 \\
\hline Tidal volume & $\begin{array}{l}\text { mechanically ventilated patients } \\
\text { with consolidation }\end{array}$ & $\begin{array}{l}<550 \mathrm{ml} \\
>550 \mathrm{ml}\end{array}$ & $\begin{array}{l}16 \\
15\end{array}$ & $\begin{array}{l}38 \pm 40 \\
25 \pm 31\end{array}$ & 0.6 & $\begin{array}{l}2.8 \pm 2.2 \\
1.9 \pm 1.3\end{array}$ & 0.2 \\
\hline $\begin{array}{l}\text { Respiratory } \\
\text { rate }\end{array}$ & $\begin{array}{l}\text { mechanically ventilated patients } \\
\text { with consolidation }\end{array}$ & $\begin{array}{l}\leq 18 \text { breaths } / \mathrm{min} \\
>18 \text { breaths } / \mathrm{min}\end{array}$ & $\begin{array}{l}17 \\
15\end{array}$ & $\begin{array}{l}32 \pm 39 \\
29 \pm 33\end{array}$ & 0.8 & $\begin{array}{l}2.0 \pm 1.8 \\
2.8 \pm 1.9\end{array}$ & 0.1 \\
\hline
\end{tabular}

$\mathrm{p}$ values are indicated (Mann-Whitney $\mathrm{U}$ test). Means \pm SD. NA = Not applicable: $\mathrm{p}$ value not reliable because of the small sample of non-ventilated patients with consolidation or congestion.

monia patients than in normal subjects. Their acoustic data analysis revealed that $81 \%$ of the pneumonia patients had inspiratory crackles at a frequency of $309 \pm 63 \mathrm{~Hz}$. While most of this signal may be filtered by the band pass used in our analysis $(150-250 \mathrm{~Hz})$, residual adventitious sounds may contribute to the elevated lung vibration intensity in patients with consolidation. Another factor that may partly explain the increase in vibration intensity in this patient population is bronchial breathing. Indeed, Gross et al. [40] introduced computer-based detection of bronchial breathing as a useful part of quantitative monitoring of patients at risk to develop pneumonia. Finally, secretions may also contribute to this increase as the association between secretions and pneumonia was recently discussed $[41,42]$.

Our results also revealed elevated vibration intensity in mechanically ventilated patients when compared to spontaneously breathing patients. This difference may be the result of different ventilatory flow between these two modes. In our approach based on lung sounds generated by airflow, it is indeed difficult to assess whether differences in sound recorded at the chest wall result from differing acoustic properties of the lung or differing airflow rates $[43,44]$. In our study, however, differences in ventilatory status did not affect the diagnostic value of consolidations since significant differences were also obtained when limiting the comparison to mechanically ventilated patients in pressure support mode. Nonetheless, the threshold used in our study may need to be adjusted when recording patients in other ventilatory conditions, such as in modes of mechanical ventilation that may provide different baseline noise. Indeed, standardization of the source of noise may be necessary in order to minimize the effect of flow [45]. One possible option may be to compute the ratio between sound and flow. Alternatively, a different approach based on the injection of a known sound and recording of the sound transmitted to the chest wall $[46,47]$ may be applied, but this method may be less practical in critical care. 
Automated lung sound analysis has been successfully compared to standard auscultation [48], with agreement reaching $84 \%$ in obstructive disease [49]. In some instances, discrepancies between the two techniques were explained by the increased sensitivity of digitalized breath sound measurement compared to a traditional stethoscope [50]. While the use of auscultation is controversial in critical care [51], digitalized lung sound analysis has gained increasing recognition as a practical complementary tool in critically ill patients, particularly during mechanical ventilation [52]. Despite being a priori more cumbersome to implement than a standard stethoscope, automated pulmonary acoustics provide a repeatable, more objective [53], less competency-dependent assessment which is easily archived, quantified and therefore comparable [54]. While it sometimes only confirms standard expected clinical findings of physical examination, computerized lung sound analysis is clinically relevant as it objectively documents reiterated examinations, and is therefore particularly useful during treatment follow-up in intensive care.

One of the limitations of our study is the elevated standard deviations detected in all the analyses related to vibration intensity. Lung sound intensity variability in normal men was previously reported by Dosani and Kraman [55] and, recently, by Torres-Jiménez et al. [56]. Moreover, similar dispersion of the data was accounted by Dellinger et al. [38] comparing patients ventilated with different modes of mechanical ventilation. The authors reported that the vibration intensity varied between $10^{4}$ and $10^{8}$ $\mathrm{AU}$ and that the inter-patient variation was not found to be correlated with body mass index. This variability may be explained by the algorithm used to calculate lung vibration intensity as the sum of squared amplitudes in a 0.17 -second window. Another limitation includes the fact that sound was filtered to a band pass of $150-250 \mathrm{~Hz}$, which may have reduced the information available as lung sound characteristics are also contained in other frequency bands, especially $>250 \mathrm{~Hz}$. Finally, the protocol did not include a comparison of lung sound distribution with more appropriate tools, such as computerized tomography. This should be investigated in the future.

Despite these limitations, digitalized lung acoustic monitoring at the bedside may be a useful objective complementary modality to help differentiate between various lung opacities in critically ill patients. A randomized controlled study may be warranted in order to further validate the applicability of this methodology, particularly in the investigation of early pneumonia detection and during treatment follow-up.

\section{Acknowledgment}

We would like to express our gratitude to Mrs. Shlomit Mann (biostatistician) for her guidance during the statistical analysis for this study.

\section{References}

1 Rubinowitz AN, Siegel MD, Tocino I: Thoracic imaging in the ICU. Crit Care Clin 2007;23:539-573.

2 Henschke CI, Yankelevitz DF, Wand A, Davis SD, Shiau M: Accuracy and efficacy of chest radiography in the intensive care unit. Radiol Clin North Am 1996;34:21-31.

3 Costa EL, Lima RG, Amato MB: Electrical impedance tomography. Curr Opin Crit Care 2009;15:18-24.

-4 Bodenstein M, David M, Markstaller K: Principles of electrical impedance tomography and its clinical application. Crit Care Med 2009;37:713-724.

-5 Meier T, Luepschen H, Karsten J, Leibecke T, Grossherr M, Gehring H, Leonhardt S: Assessment of regional lung recruitment and derecruitment during a PEEP trial based on electrical impedance tomography. Intensive Care Med 2008;34:543-550.
6 Preis C, Luepschen H, Leonhardt S, Gommers D: Experimental case report: development of a pneumothorax monitored by electrical impedance tomography. Clin Physiol Funct Imaging 2009;29:159-162.

7 Costa EL, Chaves CN, Gomes S, Beraldo MA, Volpe MS, Tucci MR, Schettino IA, Bohm SH, Carvalho CR, Tanaka H, Lima RG, Amato MB: Real-time detection of pneumothorax using electrical impedance tomography. Crit Care Med 2008;36:12301238 .

8 Kirkpatrick AW, Šustić A, Blaivas M: Introduction to the use of ultrasound in critical care medicine. Crit Care Med 2007;35:S223S225.

-9 Šustić A: Role of ultrasound in the airway management of critically ill patients. Crit Care Med 2007;35:S173-S177.

10 Lichtenstein DA: Ultrasound in the management of thoracic disease. Crit Care Med 2007;35:S250-S261.
11 Lichtenstein D, Mezière G, Seitz J: The dynamic air bronchogram. A lung ultrasound sign of alveolar consolidation ruling out atelectasis. Chest 2009;135:1421-1425.

-12 Blaivas M, Kirkpatrick A, Sustić A: Future directions and conclusions. Crit Care Med 2007;35:S305-S307.

13 Leblanc P, Macklem PT, Ross WR: Breath sounds and distribution of pulmonary ventilation. Am Rev Respir Dis 1970;102:10-16.

14 Ploy-Song-Sang Y, Martin RR, Ross WR, Loudon RG, Macklem PT: Breath sounds and regional ventilation. Am Rev Respir Dis 1977;116:187-199.

15 Ploy-Song-Sang Y, Macklem PT, Ross WR: Distribution of regional ventilation measured by breath sounds. Am Rev Respir Dis 1978;117:657-664.

16 Murphy RL, Holford SK, Knowler WC: Visual lung sound characterization by time-expanded waveform analysis. N Engl J Med 1977;296:969-971. 
17 Kraman SS: The relationship between airflow and lung sound amplitude in normal subjects. Chest 1984;86:225-229.

-18 Charbonneau G, Sudraud M, Soufflet G: Method for the evaluation of flow rate from pulmonary sounds. Bull Eur Physiopathol Respir 1987;23:265-270.

-19 Gavriely N, Cugell DW: Airflow effects on amplitude and spectral content of normal breath sounds. J Appl Physiol 1996;80:5-13.

20 Kraman SS: Transmission of lung sounds through light clothing. Respiration 2008;75: 85-88.

-21 Fiz JA, Jané R, Izquierdo J, Homs A, García MA, Gomez R, Monso E, Morela J: Analysis of forced wheezes in asthma patients. Respiration 2006;73:55-60.

-22 Donnerberg RL, Druzgalski CK, Hamlin RL, Davis GL, Campbell RM, Rice DA: Sound transfer function of the congested canine lung. Br J Dis Chest 1980;74:23-31.

$\checkmark 23$ Kompis M, Pasterkamp H, Wodicka GR: Acoustic imaging of the human chest. Chest 2001;120:1309-1321.

-24 Charleston-Villalobos S, González-Camarena R, Chi-Lem G, Aljama-Corrales T: Acoustic thoracic images for transmitted glottal sounds. Conf Proc IEEE Eng Med Biol Soc 2007;2007:3481-3484

-25 Albuerne-Sánchez L, Charleston-Villalobos S, González-Camarena R, Chi-Lem G, Carrillo JG, Aljama-Corrales T: Base lung sound in diffuse interstitial pneumonia analyzed by linear and nonlinear techniques. Conf Proc IEEE Eng Med Biol Soc 2008;2008: 1615-1618.

26 Murphy RL, Vyshedskiy A, Power-Charnitsky VA, Bana DS, Marinelli PM, WongTse A, Paciej R: Automated lung sound analysis in patients with pneumonia. Respir Care 2004;49:1490-1497.

-27 Bentur L, Beck R, Berkowitz D, Hasanin J, Berger I, Elias N, Gavriely N: Adenosine bronchial provocation with computerized wheeze detection in young infants with prolonged cough: correlation with long-term follow-up. Chest 2004;126:1060-1065

-28 Dellinger PR, Parrillo JE, Kushnir A, Rossi M, Kushnir I: Dynamic visualization of lung sounds with a vibration response device: a case series. Respiration 2008;75:60-72.

-29 Becker HD, Slawik M, Miyazawa T, Gat M: Vibration response imaging as a new tool for interventional-bronchoscopy outcome assessment: a prospective pilot study. Respiration 2009;77:179-194.
30 Wang Z, Jean S, Bartter T: Lung sound analysis in the diagnosis of obstructive airway disease. Respiration 2009;77:134-138.

31 Marini JJ: Acoustic monitoring - super sonics? Crit Care 2009;13:162.

32 Cinel I, Jean S, Dellinger RP: Dynamic lung imaging techniques in mechanically ventilated patients; in Vincent JL (ed): Yearbook of Intensive Care and Emergency Medicine. Heidelberg, Springer, 2007, pp 373-380.

33 Lev S, Singer P, Glickman YA: Vibration response imaging: a novel technology for lung monitoring in critically ill patients; in Esquinas A (ed): Yearbook of Respiratory Care Clinics and Applied Technologies. Murcia, World Federation of Respiratory Care and Applied Technologies, 2008, pp 530-539.

34 Mor R, Kushnir I, Meyer JJ, Ekstein J, BenDov I: Breath sound distribution images of patients with pneumonia and pleural effusion. Respir Care 2007;52:1753-1760.

35 Anantham D, Herth FJ, Majid A, Michaud G, Ernst A: Vibration response imaging in the detection of pleural effusions: a feasibility study. Respiration 2009;77:166-172.

36 Blanco M, Mor R, Fraticelli A, Breen DP, Dutau H: Distribution of breath sound images in patients with pneumothoraces compared to healthy subjects. Diagnostic yield of vibration response imaging technology. Respiration 2009;77:173-178

37 Jean S, Cinel I, Tay C, Parrillo JE, Dellinger RP: Assessment of asymmetric lung disease in intensive care unit patients using vibration response imaging. Anesth Analg 2008; 107:1243-1247.

38 Dellinger RP, Jean S, Cinel I, Tay C, Rajanala S, Glickman YA, Parrillo JE: Regional distribution of acoustic-based lung vibration as a function of mechanical ventilation mode. Crit Care 2007;11:R26.

39 Lev S, Glickman YA, Kagan I, Dahan D, Cohen J, Grinev M, Shapiro M, Singer P: Changes in regional distribution of lung sounds as a function of positive end-expiratory pressure. Crit Care 2009;13:R66.

40 Gross V, Fachinger P, Penzel T, Koehler U, von Wichert P, Vogelmeier C: Detection of bronchial breathing caused by pneumonia. Biomed Tech (Berl) 2002;47:146-150.

41 Bouza E, Pérez MJ, Muñoz P, Rincón C, Barrio JM, Hortal J: Continuous aspiration of subglottic secretions in the prevention of ventilator-associated pneumonia in the postoperative period of major heart surgery. Chest 2008;134:938-946.
42 Chao YF, Chen YY, Wang KW, Lee RP, Tsai $\mathrm{H}$ : Removal of oral secretion prior to position change can reduce the incidence of ventilator-associated pneumonia for adult ICU patients: a clinical controlled trial study. J Clin Nurs 2009; 18:22-28.

43 Pasterkamp H, Kraman SS, Wodicka GR: Respiratory sounds. Advances beyond the stethoscope. Am J Respir Crit Care Med 1997;156:974-987.

44 Yosef M, Langer R, Lev S, Glickman YA: Effect of airflow rate on vibration response imaging in normal lungs. Open Respir Med J 2009;3:116-122.

45 Pasterkamp H, Powell RE, Sanchez I: Lung sound spectra at standardized air flow in normal infants, children, and adults. Am J Respir Crit Care Med 1996;154:424-430.

46 Räsänen J, Gavriely N: Detection of porcine oleic acid-induced acute lung injury using pulmonary acoustics. J Appl Physiol 2002; 93:51-57

47 Paciej R, Vyshedskiy A, Shane J, Murphy R: Transpulmonary speed of sound input into the supraclavicular space. J Appl Physiol 2003;94:604-611.

48 Murphy RLH: In defense of the stethoscope. Respir Care 2008, 53:355-369.

49 Guntupalli KK, Alapat PM, Bandi VD, Kushnir I: Validation of automatic wheeze detection in patients with obstructed airways and in healthy subjects. J Asthma 2008;45:903907.

50 Bentur L, Livnat G, Husein D, Pollack S, Rotschild M: Dynamic visualization of breath sound distribution in suspected foreign body aspiration: a pediatric case series. J Bronchol 2007;14:156-161.

51 Hubmayr RD: The times are a-changin': should we hang up the stethoscope? Anesthesiology 2004;100:1-2.

52 Caples SM, Hubmayr RD: Respiratory monitoring tools in the intensive care unit. Curr Opin Crit Care 2003;9:230-235.

53 Gasparini S: Do we really need a computerized stethoscope? Respiration 2009;77:132133.

54 Becker HD: Vibration response imaging - finally a real stethoscope. Respiration 2009;77: 236-239.

55 Dosani R, Kraman SS: Lung sound intensity variability in normal men. A contour phonopneumographic study. Chest 1983;83:628631.

56 Torres-Jiménez A, Charleston-Villalobos S, Gonzalez-Camarena R, Chi-Lem G, AljamaCorrales T: Respiratory acoustic thoracic imaging (RATHI): assessing intrasubject variability. Conf Proc IEEE Eng Med Biol Soc 2008;2008:4793-4796. 